\title{
ANÁLISE DA EDUCAÇÃO AMBIENTAL NAS ESCOLAS PÚBLICA E PRIVADA DO BAIRRO DA SACRAMENTA-BELÉM-PARÁ
}

Rafaela Caroline Barros Silva - barrosrc15@gmail.com

Universidade Federal do Pará

Fábio Sergio Lima Brito - fabio.lima.ufpa@ gmail.com

Universidade Federal do Pará

Ana Paula Gomes Mendonça -anapaulagomesmendonca03@ gmail.com

Universidade Federal do Pará

Juliana Maia Duarte - duartemaiajuliana@gmail.com

Universidade Federal do Pará

Lindemberg Lima Fernandes- linlimfer@gmail.com

Universidade Federal do Pará 


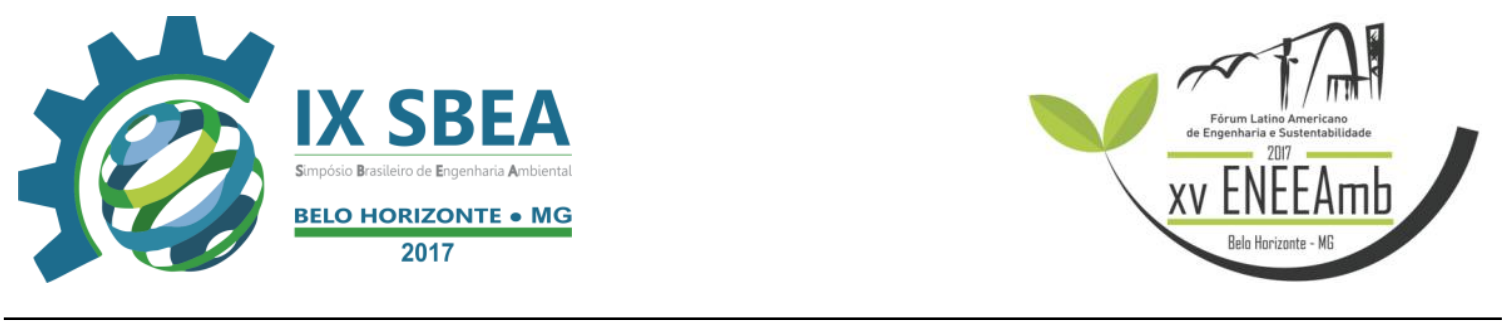

\section{RESUMO}

A lei $N^{\circ} 9.795$ de 27 de abril de 1997, apresenta a definição de Educação Ambiental (EA) e a indica como necessária em todas as esferas de ensino. Sendo assim, o presente artigo visa verificar a aplicabilidade da lei supracitada em duas escolas sendo uma Pública e outra Privada de um bairro populoso e periférico da Região Metropolitana de Belém (RMB)-PA. Os procedimentos da pesquisa compreendem: levantamento bibliográfico e elaboração de questionário contendo perguntas objetivas e de múltiplas escolhas, aplicados aos alunos de duas unidades de ensino, no ano de 2016, afim de verificar o conhecimento dos mesmos quanto ao conceito de EA, se a temática é trabalhada nas escolas; os meios utilizados e se os alunos possuem interesse pela área. Os resultados apresentam-se claros, alertando para a falha na implementação da lei e a necessidade de medidas paliativas, visto que, os envolvidos na pesquisa demostraram interesse em conhecer um pouco mais sobre a temática e consideram como algo relevante para discursão no ambiente escolar. Diante do contexto foi apresentado medidas viáveis de curto e médio prazo para se inserir e/o amadurecer o assunto nas Escolas para posterior aplicabilidade na vida cotidiana dos alunos. Uma vez que, algo tão emergente deve ser tratado com prioridade.

Palavras-chave: lei № 9.795 de 27 de abril de 1997, Educação ambiental, Escolas pública e privada.

\section{INTRODUÇÃO/OBJETIVO}

Diante das preocupações com as questões ambientais no atual cenário mundial, vê-se que as discussões têm se tornado cada vez mais frequentes, desde meras especulações até um diagnóstico de uma determinada realidade dos desequilíbrios ecológicos (SOUSA; JUVÊNCIO, 2016).

Diante desse processo, a escola ganha uma importância única, pois as crianças quando bem informadas sobre os problemas ambientais farão parte de uma sociedade mais justa e preocupada com a questão ambiental. Nesse sentido, a Educação Ambiental (EA) no âmbito escolar possibilita a preparação do indivíduo para exercer sua 


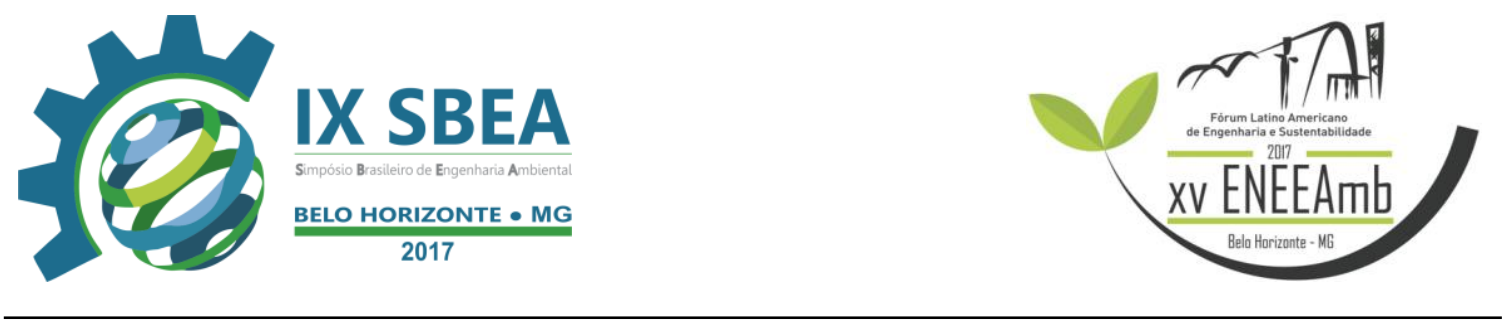

cidadania, sendo caracterizada como educação ambiental formal (MEDEIROS et al, 2011).

Segundo Virgens (2011), é no espaço escolar que ocorre as principais discussões e o aprendizado de vários temas que contribuem para a formação de cidadãos mais conscientes. Apesar de a EA ter que está inserida no ambiente escolar ela deve ser vista e trabalhada de forma interdisciplinar em todas as matérias, não apenas em ciências e biologia.

Pessoa e Braga (2010), afirmam que com a prática da EA busca-se sensibilizar e aumentar a percepção dos indivíduos para que se tornem mais responsáveis na construção de um modo de vida com mais qualidade.

Nesse sentido, a Lei No 9.795 de 27 de abril de 1999, que além de definir educação ambiental, aponta-a como componente essencial e permanente em todos os níveis e modalidades de ensino, cujo caráter humanista, participativo e democrático engloba a interrelação de aspectos econômicos, políticos, culturais, e sociais a fim de construir uma sociedade ambientalmente equilibrada.

Sendo assim, é preciso mais que conhecimento, é necessário que a escola assuma seu compromisso de trabalhar com formação de valores e atitudes que favoreçam a adoção de novos comportamentos e hábitos pró-ambientais (FRANCO, 2012).

Por isso, o presente trabalho tem por objetivo analisar e verificar a aplicabilidade da lei de EA em duas escolas sendo uma pública e outra privada localizadas no bairro da Sacramenta na cidade de Belém do Pará, bem como, avaliar se os alunos possuem conhecimento quanto ao conceito de EA e esse tema é abordado nas escolas.

\section{METODOLOGIA}

\subsection{Local de Estudo:}

O bairro da Sacramenta está localizado na cidade de Belém do Pará, ocupa uma área de 237,33 hectares, tem uma população estimada de 44.413 habitantes, o que representa 3,19\% da população do município de Belém, de acordo com o censo de 2010 


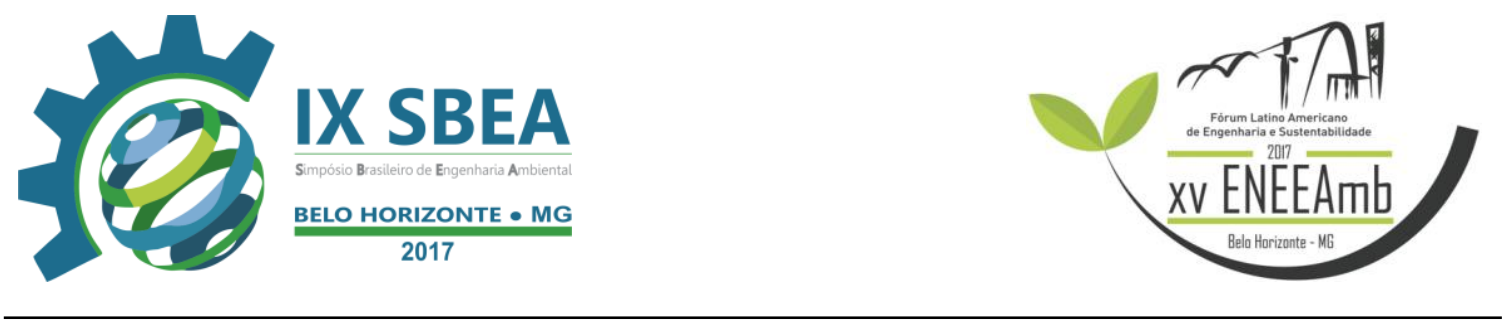

do IBGE (Instituto de Geografia e Estatística). É considero ainda como um bairro que ocupa oitava posição entre os maiores bairros da cidade de Belém.

\subsection{Pesquisa Bibliográfica:}

Os levantamentos sobre o tema e assuntos foram pesquisados em: sites, artigos e trabalho de conclusão de curso (TCC) que conduziram a uma reflexão teórica sobre EA em escolas e sua aplicabilidade.

\subsection{Coleta de dados:}

Para coleta de dados foi realizada uma pesquisa com alunos de duas escolas de ensino médio, onde uma é da rede privada e a outra da rede pública, localizadas no bairro da Sacramenta - Belém-PA.

Afim de preserva a identidade das Escolas, as identificamos como escola $\mathrm{x}$ (privada) e escola y (pública). Com as escolas já definidas, foi elaborado um questionário contento 12 perguntas sobre educação ambiental e assuntos relacionados, como: resíduos sólidos, coleta seletiva, economia de água e desenvolvimento sustentável.

Participaram da pesquisa 31 alunos do ensino médio da rede particular (X) representando $24 \%$ do total de alunos do turno da manhã daquela instituição e 43 alunos do ensino médio da rede pública (Y) representando 35\% do total de alunos do turno da tarde desta instituição.

\section{RESULTADOS E DISCUSSÃO}

Com aplicação dos questionários nas áreas de estudo foi possível analisar o grau de conhecimento dos alunos das escolas pública e privada, quanto ao tema Educação ambiental, bem como sua implantação nas redes de ensino e os métodos utilizados para a sua trabalhabilidade.

Sendo assim, traçou-se um perfil dos alunos, que participaram do estudo, com relação ao sexo, como mostra os gráficos 1 e 2 . É possível visualizar que tanto na escola 


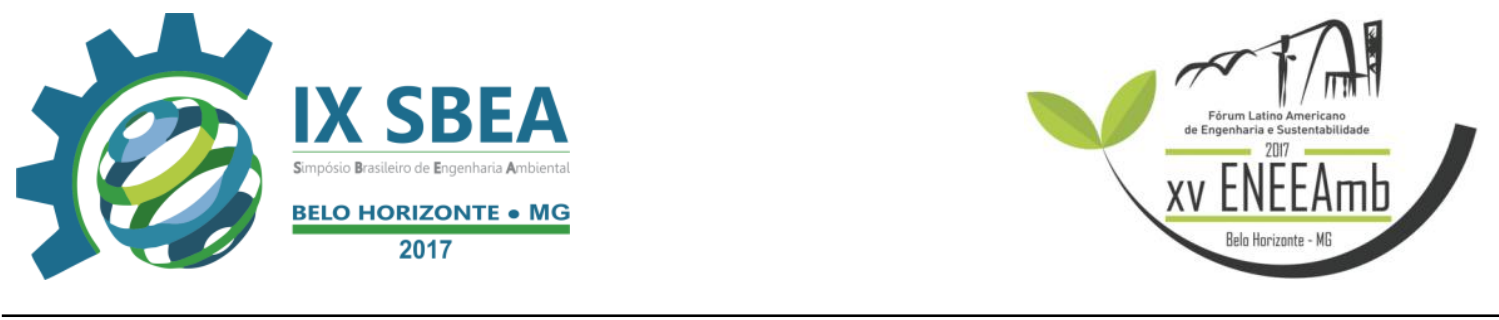

$X$, assim como, na escola y não houve uma predominância de sexo, já que contamos com uma quantidade considerável para expressar a opinião de ambos os lados.

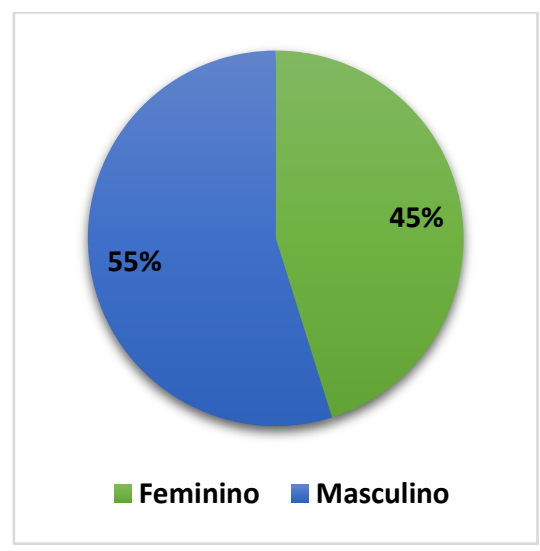

Gráfico 1. Sexo dos alunos na escola X

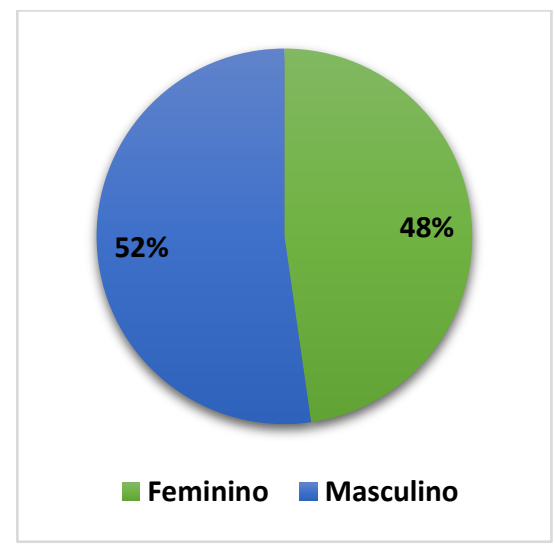

Gráfico 2. Sexo dos alunos na escola Y

Tanto na escola $\mathrm{X}$ como na $\mathrm{Y}$ o desconhecimento quanto ao conceito de educação ambiental foi bem alto, demonstrando que pouco ou quase nada da temática em questão é trabalhado nas unidades de ensino, e consequentemente a fragilidade na lei, além do desinteresse por parte dos gestores (professores e corpo técnico), em trabalhar tal tema, tão importante e relevante para o contexto social e econômico da sociedade atual e futura (Gráficos 3 e 4).

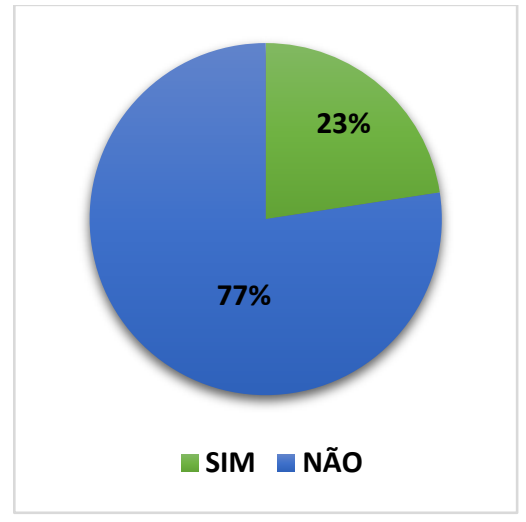

Gráfico 3. Conhecimento do conceito de EA na escola $X$

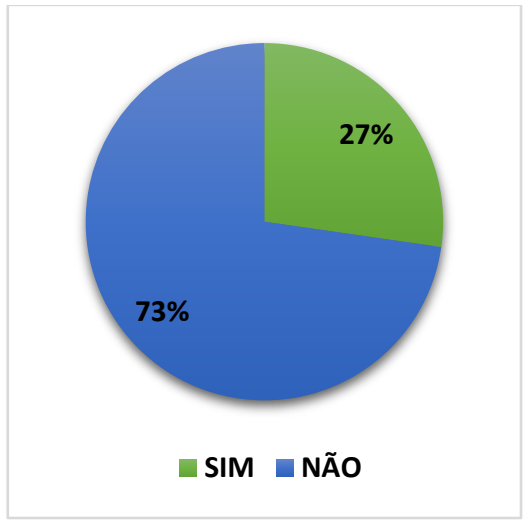

Gráfico 4. Conhecimento do conceito de EA na escola $Y$ 


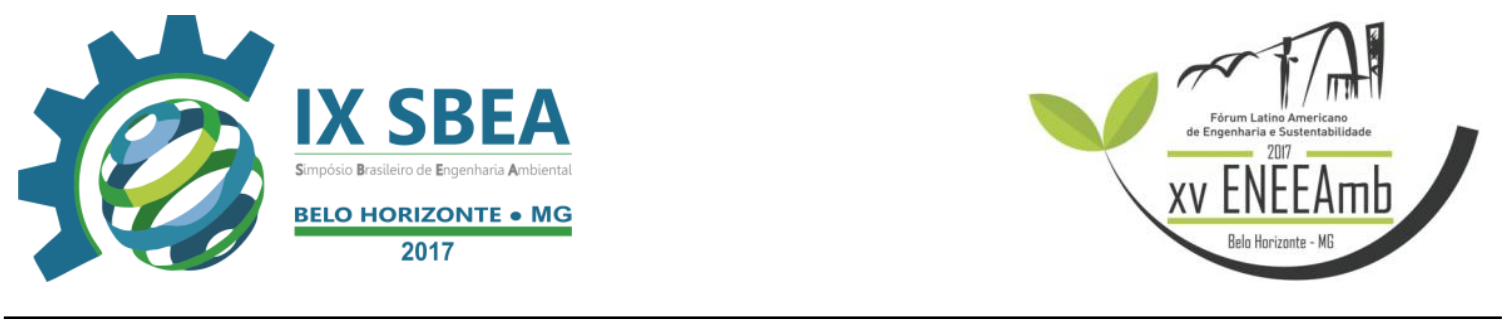

Quando questionados se a escola desenvolve atividade relacionadas ao meio ambiente os resultados mostram a carência de ações voltadas ao meio ambiente, bem como a falha na implementação da lei no ambiente escolar. Apesar de sua detectação em outras situações, por parte de alguns envolvidos na pesquisa, a ineficiência e/ou carência é nítida, já que mais da maioria dos alunos desconhece a aplicabilidade da atividade nas unidades de ensino, tal leitura se aplica para ambas escolas (Gráficos 5 e $6)$.

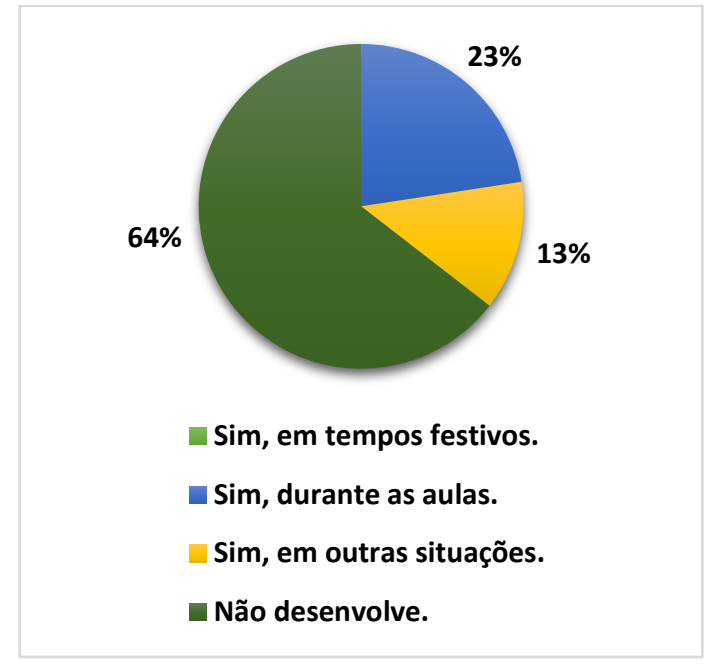

Gráfico 5. Conhecimento dos alunos em relação a atividades voltadas para o meio ambiente na escola $X$

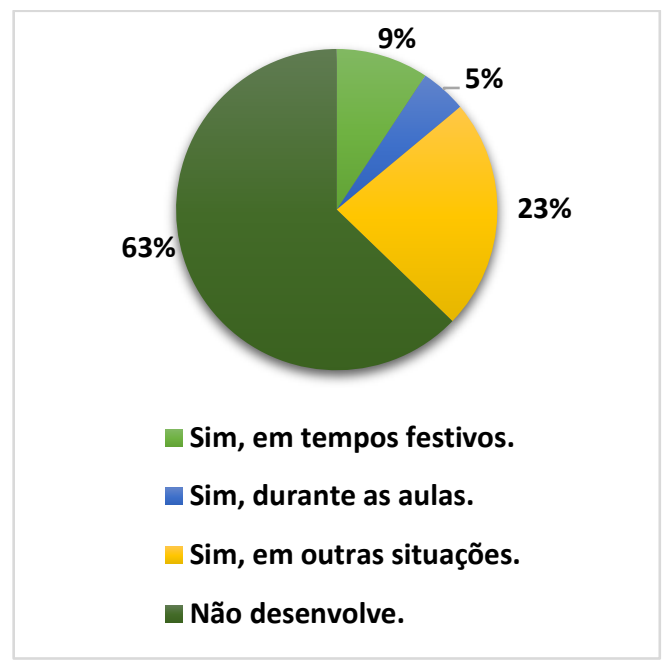

Gráfico 6. Conhecimento dos alunos em relação a atividades voltadas para o meio ambiente na escola Y

Quando indagados quais os meios utilizados para o desenvolvimento de atividade ligadas ao meio ambiente. Os alunos listaram várias opções como alternativa que demostram a aplicabilidade ou trabalhabilidade do assunto, sendo ainda em pequena escala e/ou parcial, uma vez que os meios indicados foram pouco reconhecidos, indicando a real necessidade de buscar aprimora-los, nas esferas indicadas (Gráficos 7 e 8). 

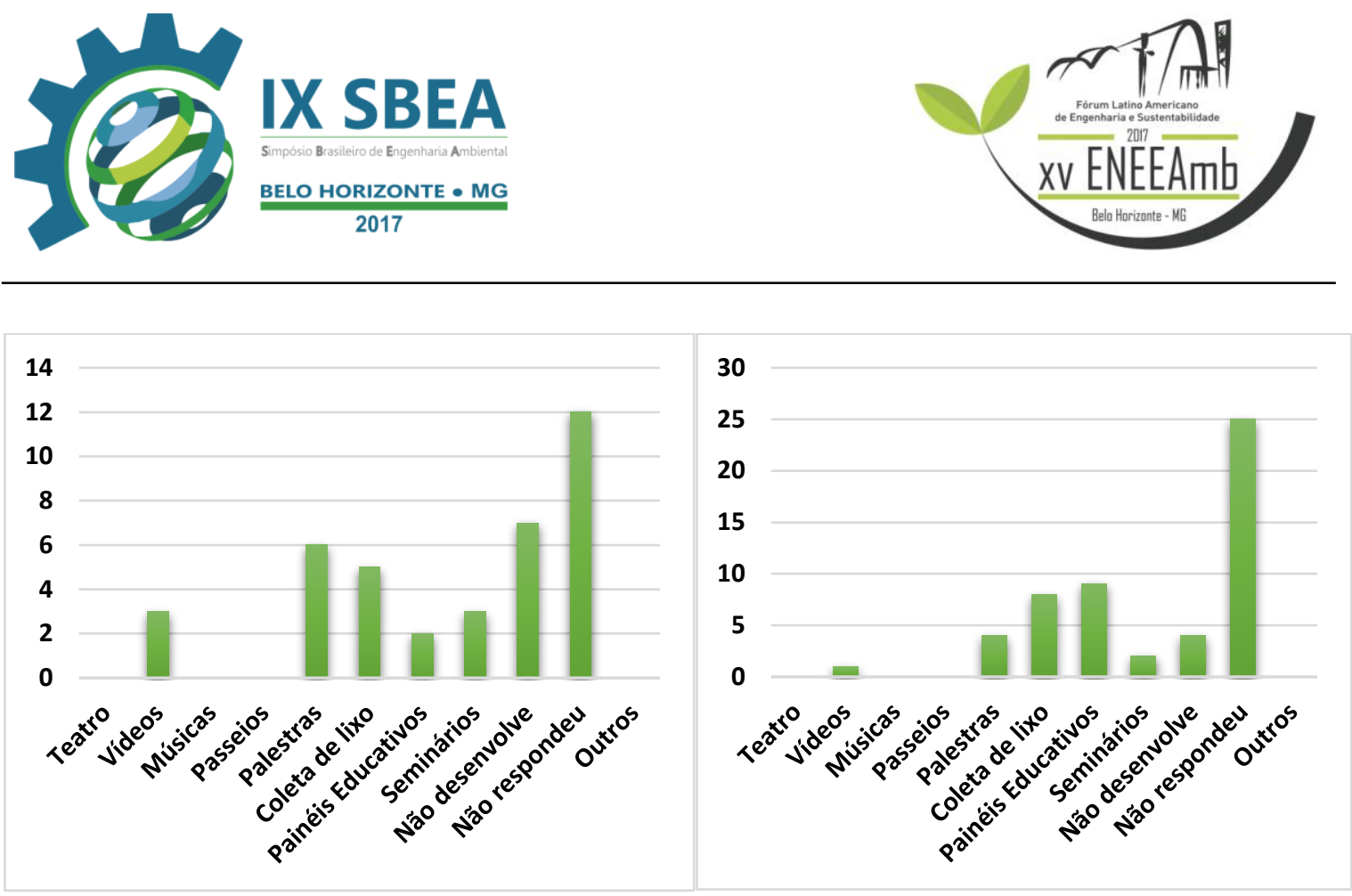

Gráfico 7.Meios utilizados nas atividades

Gráfico 8.Meios utilizados nas atividades voltadas para o meio ambiente na escola $\mathrm{X}$ voltadas para o meio ambiente na escola $\mathrm{Y}$

Quando perguntados sobre os espaços arborização nas escolas, horta ou jardim os resultados mostram a ausência de espaço verde, e a necessidade de áreas voltadas para a conservação do meio ambiente. Tal situação apresenta-se como preocupante e emergente, uma vez que, umas das maneiras simples de demostram interesse por questões ambientais é a preservação e tentataviva de implementação de áreas arborizadas, e por sinal nas escolas assinaladas esse assunto não foi visto como prioridade. O que vem realçar a carência de práticas ambientais, bem como a falta de interesse dos gestores e professores em estimular ações voltadas para o meio ambiente.

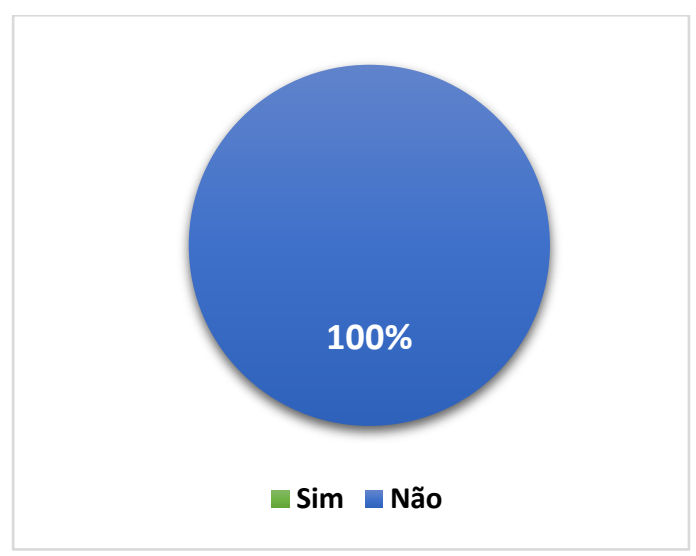

Gráfico 9. Quanto aos espaços de arborização, horta e jardim nas escolas X e Y 


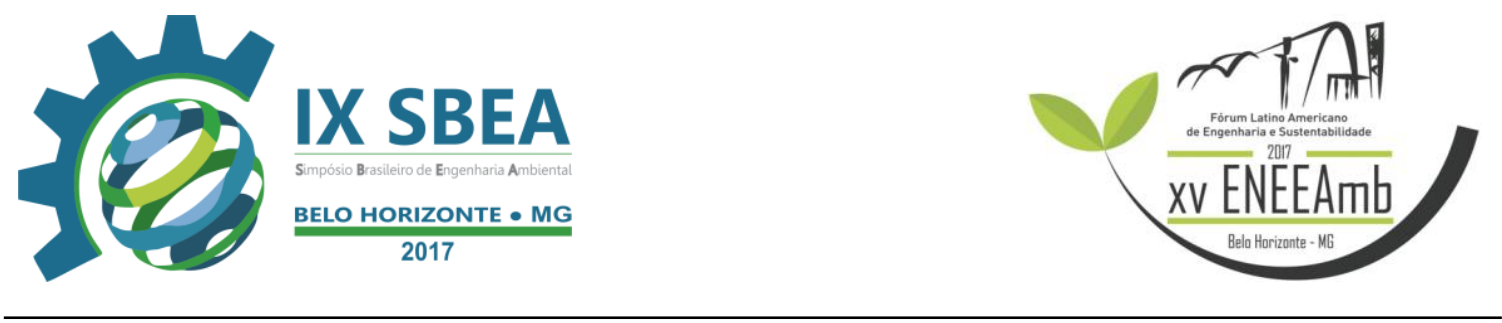

Quanto a presença de coleta seletiva (lixeiras coloridas) é possível observar no gráfico 10 que nas duas escolas analisadas não existe a separação de resíduos, indicando o rejeito inadequado e a falta de conscientização por parte do corpo técnico das escolas, resultando na falta do conhecimento e aplicabilidade do termo coleta seletiva, tão essencial para o processo de reciclagem (Gráfico 10).

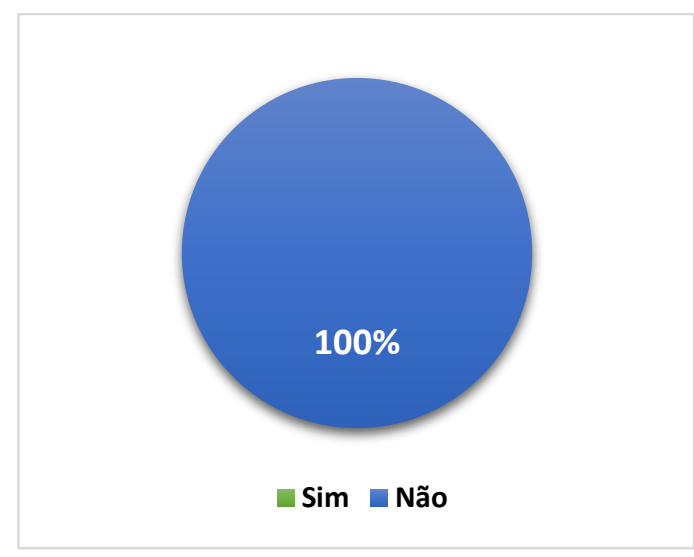

Gráfico 10. Presença de coleta seletiva nas escolas X e Y

Os gráficos 11 e 12 mostram as perguntas com relação a ações voltadas para o uso racional da água na qual é possível analisar que a falta de práticas relacionadas a conservação do meio ambiente e consequentemente a carência de adolescente com uma formação crítica perante as problemáticas ambientais e sociais.

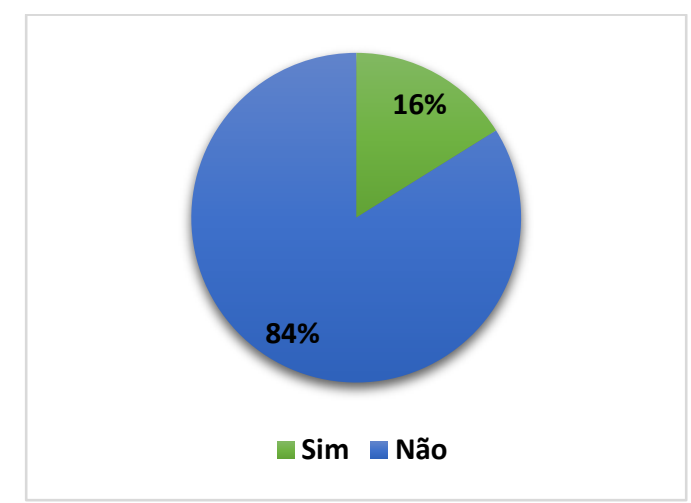

Gráfico 11. Campanhas de uso racional da água na escola X

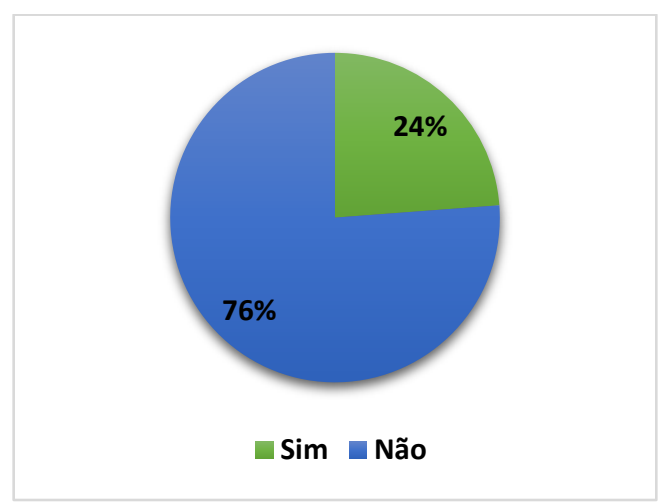

Gráfico 12. Campanhas de uso racional da água na escola $\mathrm{Y}$ 


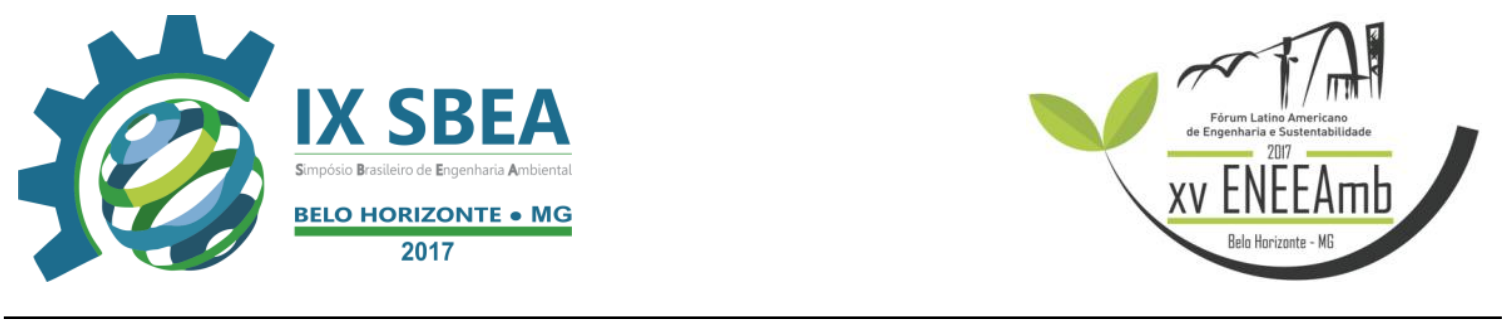

Quando perguntados se tinham interesse em participar de ações que envolvam o meio ambiental. Os resultados são bem satisfatórios, indicando uma aceitabilidade dos envolvidos na pesquisa, em participar de projetos que envolvam o meio ambiente. Demostrando a compreensibilidade dos alunos, quanto a suma importância da discursão e trabalhabilidade da questão (Gráficos 13 e 14).
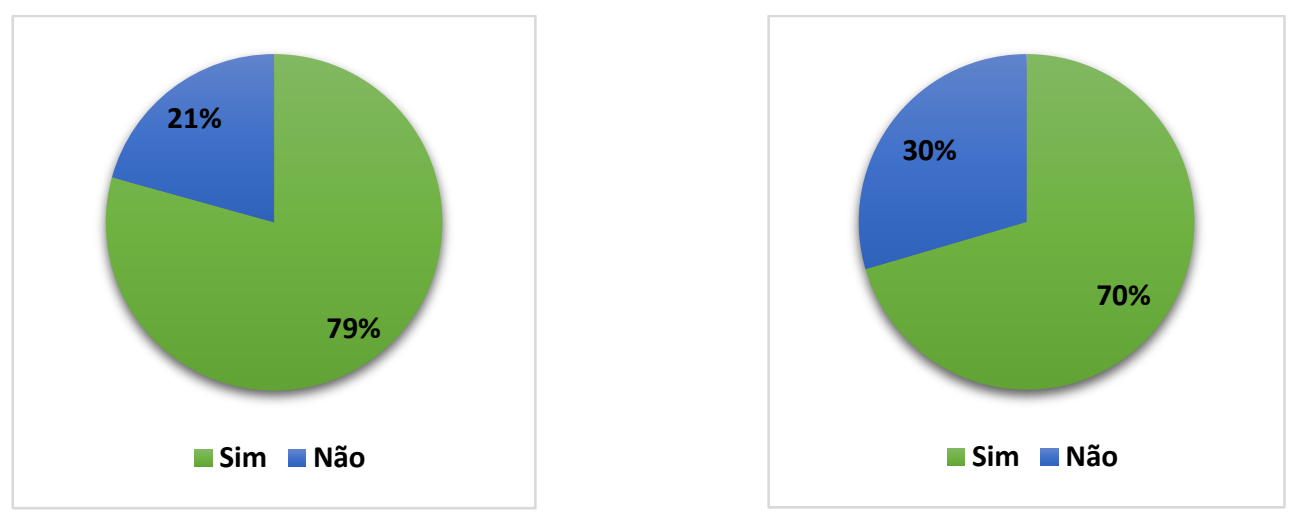

Gráfico 13. Interesse em participar de ações Gráfico 14. Interesse em participar de ações de EA na escola $X$ de EA na escola Y

\section{CONCLUSÕES/RECOMENDAÇÕES}

A realização do trabalho tem por objetivo verificar se os alunos possuem conhecimento quanto ao conceito de Educação Ambiental, como é trabalhado a temática e os métodos utilizados nas Escolas pública e privada do bairro da Sacramenta-BelémPA.

As análises dos resultados mostram que as unidades de ensino apresentam problemáticas quanto a divulgação e trabalhabilidade do tema nas escolas. Deixando explicito a carência do assunto, nos ambientes pesquisados. Tal situação é bastante preocupante se pensamos em fazermos uma projeção e estender os resultados para as demais unidades de ensinos do bairro.

Pois, uma questão tão contemporânea e essencial para a vida e preservação da vida do ser humano, deixada em segundo ou terceiro plano é algo a se questionar, qual modelo de desenvolvimento buscamos? Será que estamos indo pelo caminho certo? O que almejamos com essas atitudes? 


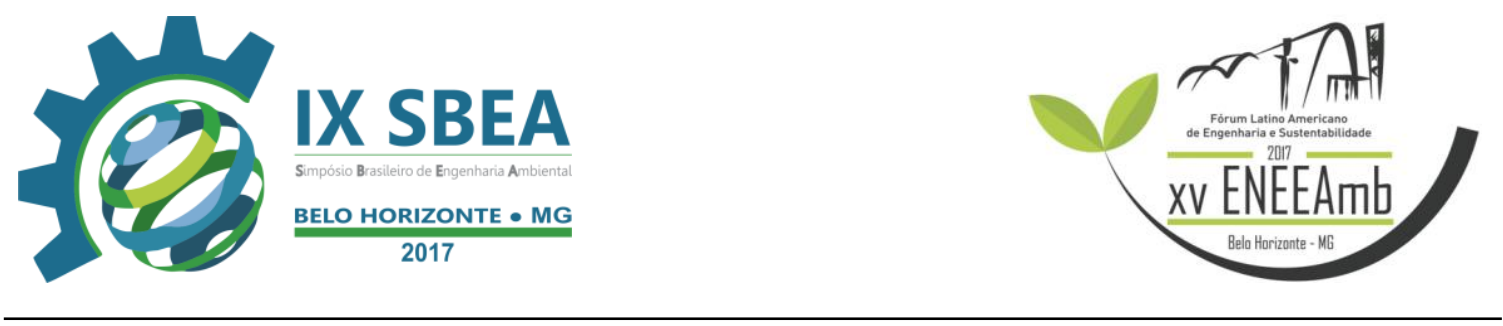

Neste sentido, torna-se necessário que o corpo técnicos das escolas busquem implantar ações que envolvam o meio ambiente, uma vez que os alunos mostraram-se motivados em conhecer um pouco mais sobre o tema, além de apresentarem interesse em participar de ações que envolvem EA.

Vale ressaltar que é viável a realização de cursos, pelos professore e técnicos, que envolvam questões ambientais. Para que possam desenvolver e trabalhar melhor o tema no ambiente escolar, e consequentemente os alunos se sentirem motivados conhecer mais sobre o assunto e repensar sobre suas atitudes.

\section{REFERÊNCIAS BIBLIOGRÁFICAS}

BRASIL, MINISTÉRIO DO MEIO AMBIENTE. Lei Nº 9.795, de 27 de abril de 1999.

FRANCO, E. A S. Projeto Escola \& Universidade: Fortalecendo a Educação Ambiental Multidisciplinar nas Escolas. Revista Eletrônica Educação Ambiental em Ação, n. 41, 2012

LEITE et al. Educação ambiental: percepção e sensibilização dos alunos $9^{\circ}$ ano da escola Cenecista João Régis Amorim sobre o resíduo de óleo de cozinha usado. III Congresso Nacional de Educação Ambiental e o V Encontro Nordestino de Biogeografia, 2013.

MEDEIROS, et al. A importância da educação ambiental na escola nas séries iniciais. Revista Faculdade Montes Belos. v. 4, n.1, 2011.

PESSOA, G. P; BRAGA, R. B. Educação Ambiental escolar e qualidade de vida: desafios e possibilidades. Revista Eletrônica Mestrado Educação Ambiental. v. 24, p.143. 2010.

SOUSA, J.B; JUVÊNCIO, V.L.P. avaliação da educação ambiental na escola infantil: o caso do núcleo de desenvolvimento da criança. III Congresso Nacional de Educação Ambiental e o V Encontro Nordestino de Biogeografia, 2016.

VIRGENS, R. A. A educação ambiental no ambiente escolar. Monografia apresentada a Universidade Estadual de Goiás. 2011. 